\title{
Article \\ The Effects of the Visual Environment on K-12 Student Achievement
}

\author{
Michael Kuhlenengel *, Iason Konstantzos (D) and Clarence E. Waters
}

check for updates

Citation: Kuhlenengel, M.;

Konstantzos, I.; Waters, C.E. The

Effects of the Visual Environment on K-12 Student Achievement. Buildings 2021, 11, 498. https://doi.org/ 10.3390/buildings11110498

Academic Editors: Gerardo Maria Mauro and Cinzia Buratti

Received: 17 September 2021

Accepted: 14 October 2021

Published: 21 October 2021

Publisher's Note: MDPI stays neutra with regard to jurisdictional claims in published maps and institutional affiliations.

Copyright: (c) 2021 by the authors. Licensee MDPI, Basel, Switzerland. This article is an open access article distributed under the terms and conditions of the Creative Commons Attribution (CC BY) license (https:/ / creativecommons.org/licenses/by/ $4.0 /)$.
Durham School of Architectural Engineering and Construction, University of Nebraska-Lincoln, 1110 S. 67th St. Omaha, NE 68182-0816, USA; iason.konstantzos@unl.edu (I.K.); cwaters2@unl.edu (C.E.W.)

* Correspondence: mkuhlenengel258@huskers.unl.edu

Abstract: The varying indoor environments among educational buildings can have an impact on students' ability to learn. This study looks at field data from 220 classrooms in the Midwest, United States, over a two-year period, to analyze the effects of the visual environment on student achievement. The visual environmental metrics considered within this scope include the three new view metrics introduced within the EN 17037 "Daylight of Buildings" standard (Horizontal Sight Angle, Outside Distance of View, and Number of View Layers), as well as standard daylight and electric lighting metrics, focusing on light availability and glare. To capture student achievement, math and reading achievement scores were used, accompanied by auxiliary demographic variables. This allowed for a correlational analysis using multivariate regression. Among the notable results of this study, there was a positive effect of the availability of view on reading achievement. However, another view metric, Horizontal Sight Angle, showed a significant negative interaction with free and reduced lunch recipients on reading achievement, indicating that demographics can also have a significant role in the way the visual environment can affect learning.

Keywords: visual environment; student achievement; classroom environment

\section{Introduction}

Building environments can influence occupants' mood [1], health [2,3], and performance [4-6]. For the case of primary and secondary educational institutes, also known as K-12 educational institutions in the US, there is a particular interest in the effects of the built environment, as it can have implications on student achievement [4,7]. Building age has often been used as a proxy for more refined measures of building condition. Bowers and Burkett compared two facilities of different ages and found that students in the modern building scored significantly higher in reading, listening, language, and arithmetic tasks than students in the older facility [8]. They also found that less discipline was needed in the newer building, which also showed significantly higher attendance. Phillips found the same significant achievement score differences for reading and arithmetic with new buildings compared to older ones [9]. These studies support similar findings of older research by Plumley [10] and Chan [11]. In order to better understand the way building age acts as a proxy for the school's condition, architects and engineers focused on assessing the building's condition using more detailed factors. In 2008, Durán-Naruki gathered information from 1997 to 1998 about New York schools and compared building condition and poor academic achievement. The building conditions that were visually inspected and rated by engineers and architects included the windows, walls, furniture, mechanical system, plumbing, and building structure [5]. The study found attendance to function as a mediator for building condition and poor academic achievement. In that sense, higher scores for building condition led to higher attendance, while higher attendance decreased the number of students with poor academic achievement. Although the environmental conditions of a building refer to the lighting, thermal, and acoustical environment, as well 
as indoor air quality, this study solely examines the impact of the visual environment on student achievement, focusing on lighting and outside view.

The visual environment in particular has been thoroughly examined in office settings in a multitude of experiments with correlational analysis on lighting effects. Early research mostly dealt with the perception of lighting. Occupants reported that they believe daylight contributes to a healthier and more comfortable working environment, with reduced eye strain being listed as the top benefit [12]. A quadratic relationship was found between sunlight penetration and relaxing, indicating that daylight has a positive effect, although at very high levels it would lead to discomfort [13]. Lighting and views effects have been shown to have physical and psychological benefits as well. Views to nature have been found to have improved the level of attention when preforming the Necker Cube Pattern Control test over an urban view [14], while interesting views were also found to lessen the impact of discomfort glare [15]. View quality was found to reduce physical and psychological discomfort in office workers [3]. This study also found that sitting too close to the windows can increase the instances of problematic lighting conditions (e.g., glare/reflections from the computer screen and unwanted heat from the sun). In regard to electric lighting in offices, a separate study showed lighting conditions using direct/indirect systems were found to be more comfortable than the direct lighting systems [16]. While no main effect was found between lighting quality and performance, a follow up study by Veitch et al. showed that lighting conditions that improved visibility also improved task performance [17]. It was also reported that people who perceived their office lighting as high quality rated the spaces as more attractive and scored higher with respect to mood and well-being.

Despite the availability of studies related to office settings, visual environmental research focused on schools is limited to a small number of correlational studies related to student performance and a few experiments. Daylighting was found to increase student performance in middle school and elementary school spaces in a building with efficient daylight controls based on south facing roof monitors [18]. This design can eliminate potential glare occurrences from the sun by reflecting direct sunlight down the walls of the monitor [19]. One of the few experiments conducted on elementary school students showed that full spectrum Duro-test Vita-lite in a light blue room dramatically decreased blood pressure and off-task behavior in students. The control room was a white room with cool-white fluorescents [20]. Research by Wohlfarth [21], London [22], and Hathaway, Hargreaves, Thompson, and Novitsky showed similar findings with the full spectrum Duro-test Vita-lite being beneficial [23]. While the benefits of full spectrum light sources have been found to be marginal or even non-significant when compared to a more standard $4000 \mathrm{~K}$ Correlated Color Temperature (CCT) fluorescent fixture [24], when compared to lighting solutions of poorer quality such as high-pressure sodium [23], differences in student achievement were still significant, indicating that quality of light does matter for achievement. A 1999 study by the Heschong Mahone Group found that daylighting, as evaluated by trained architects, had a significant positive effect on both math and reading scores [4]. However, in a later study in 2003, daylighting appeared to have a negative impact on student achievement scores for math and reading [4]. In order to determine the reason for the contradicting results, an additional analysis was performed in the daylit classrooms, expanding their monitoring to also include more acoustic considerations. They found that the acoustics of the highly rated daylight rooms were poor, and many had operatable windows allowing outside noise in. They determined that the poor acoustics maybe a contributing factor for this inconsistency, revealing the need to also study interacting effects between indoor environmental parameters. The 2003 study also gathered far more data than just daylighting in the Fresno school district, and included lighting, acoustics, and indoor air quality factors. The lighting factors, outside of daylight, included glare from windows showing a negative effect on math, orientation of windows on the east and south having negative effects on reading, and vegetation views having positive effects for math and view activity level (a measure reported by classroom evaluators) outside for reading. 
The study also found that the use of luminaires with CCT lower than $3500 \mathrm{~K}$ as well as mixed fluorescent lamps had a negative effect on reading achievement scores. CCT lighting at $5500 \mathrm{~K}$ was found to promote visual acuity for elementary school children compared to $3600 \mathrm{~K} \mathrm{CCT}$ at equal task luminance [25]. Similar results were also shown with third graders and a focus lighting condition of (6000 K-1000 lux) and a normal condition (3500 K500 lux), indicating students in the focus group had a higher oral reading fluency than the normal condition [7]. Higher color temperatures and higher illuminance levels were also found to increase student concentration [26]. Concentration in blue-enriched white lighting (14,000 K CCT uplight with $4000 \mathrm{~K} \mathrm{CCT} \mathrm{downlight)} \mathrm{was} \mathrm{also} \mathrm{found} \mathrm{to} \mathrm{be} \mathrm{higher} \mathrm{than} \mathrm{in} \mathrm{a}$ standard lighting condition (3500 K CCT down) [27]. Overall, increasing lighting quality has been found to be beneficial, as students who perceive that their learning environment has high lighting quality demonstrated higher student learning performance [28].

The work presented in this paper is conducted under a research grant entitled "School Environmental Effects on Student Achievement (SEESA)". Although the SEESA project focuses on the overall indoor classroom environment, including acoustics, indoor air quality, thermal comfort, and visual environment for 220 classrooms, this study focuses on the visual environment; to that end, visual data was gathered using both occupied logging during multiple school days and unoccupied measurements along with simulations in K-12 classrooms, allowing for several different metrics to be assessed, including daylighting, electric lighting, and view variables. Student achievement and demographic data were provided at the classroom level to understand how the lighting metrics impact student achievement. The ability to capture a multitude of variables allowed for better understanding about the dynamic aspects of the visual environment throughout the day. Previous research in that area has had (i) limiting factors, such as using trained raters to evaluate spaces in classrooms [4,5,24], (ii) conflicting results between school districts [4,24], or (iii) did not eliminate confounding factors, such as daylight [23,24]. Additional deficiencies of previous studies were caused by technical limitations, such as the limited ability to create computer simulated daylight models to capture variables, positions that were not possible to be measured, or unavailability of the proper equipment to evaluate buildings in more depth. This study investigates the impact of visual environmental parameters on student learning by using occupied data that better represents the visual experience of students, creating detailed daylight simulation models to account for occurrences where field measurements were not possible, and evaluating the view from the classrooms. The results of this study aim to lead to a better understanding of the visual environment, towards better design and operation standards for classroom environments that are beneficial to learning.

\section{Materials and Methods}

\subsection{Research Design}

The research study is a correlational study between indoor visual environmental factors and student achievement. Math and reading scores are used for the assessment of student achievement. The study is based on a classroom-level analysis rather than studentlevel analysis. This approach was chosen for two primary reasons: (i) all environmental variables were measured at the classroom level; and (ii) a classroom analysis provided additional privacy for individual students, as school districts did not have to provide any student level information.

\section{Participants}

Two hundred and twenty classrooms were assessed for indoor visual environmental factors in the states of Nebraska and Iowa. Classrooms were selected from five different school districts with 144 elementary school classrooms, 32 middle school classrooms, and 44 high school classrooms. Only classrooms from grades 3rd, 5th, 8th, and 11th were selected. This was due to the fact that, when the project started in 2014, some school districts were not testing both math and reading achievement in every grade. Middle school and high school classrooms measured were either rooms for math or English teaching, as 
combined classrooms did not exist for the sampled school districts. Four classrooms were excluded from the analysis to maintain balance in our experimental design: (i) two high school classrooms, as they were not solely math or English classrooms and served other purposes; and (ii) two classrooms that had been modified for students in special education.

\subsection{Measurement Procedure and Data Acquisition}

All measurements were conducted over a two-year period, spanning from September 2015 to May 2017, measuring 110 classrooms each school year for a total of 220 classrooms. Each classroom was assessed during fall, winter, and spring, considering occupied and unoccupied conditions in each season. Each occupied measurement set included $36 \mathrm{~h}$, starting in the morning before school started and ending after two completed school days. Unoccupied measurements were conducted outside the schools' regular schedule to capture variables that are not influenced by the presence of students within the classrooms, for example, the geometry of the room or the work plane illuminance level from the electric lighting.

\subsubsection{Occupied Measurements}

Occupied lighting measurement equipment included five HOBO U12-012 illuminance meters for each classroom, as shown in Figure $1 \mathrm{a}, \mathrm{b}$, along with other instruments related to thermal comfort, indoor air quality, and acoustics. The measurement kit and stand, as shown in Figure 1a (left) allowed for meters to be placed at desk height while keeping them out of the reach of the students. In that sense, the measurement kit was placed by the teacher's desk or in the front of the room, where only individual students would approach at any given time. The kit included one illuminance meter to measure illuminance over time at the work plane height in five-minute intervals. Two of the four other illuminance meters were placed in or on the light fixtures, covering different lighting zones and giving information about operation status; as all classrooms were using fluorescent luminaires, the most common control option was three-level switching. By placing illuminance meters in the fixtures, we were able to determine how each zone was controlled and the luminaires' output levels. Figure $1 \mathrm{c}$ shows an example floor plan of where the equipment would be placed in the classroom. The study consists of three main classroom floor plan categories: the largest group is shown in Figure 1c, the second group includes one or two windows on a single wall, and the smallest group has no windows. The lighting systems installed in the classrooms were all similar, with over $90 \%$ being $2^{\prime} \times 4^{\prime}$ recessed fluorescent fixtures and the rest being surface mounted linear fluorescent fixtures.

(a)

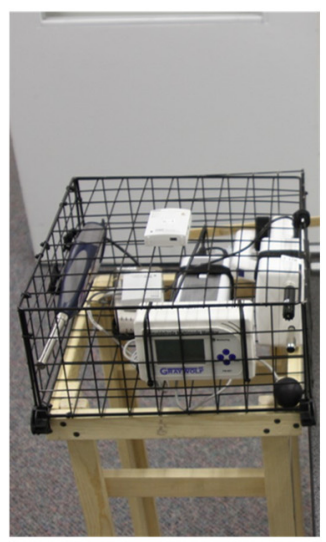

(b)

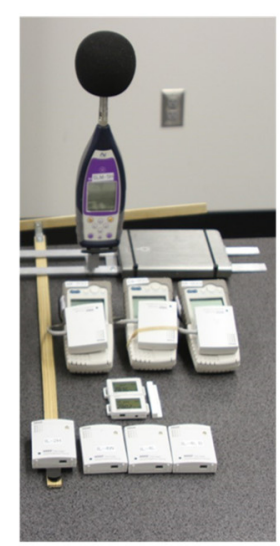

(c)

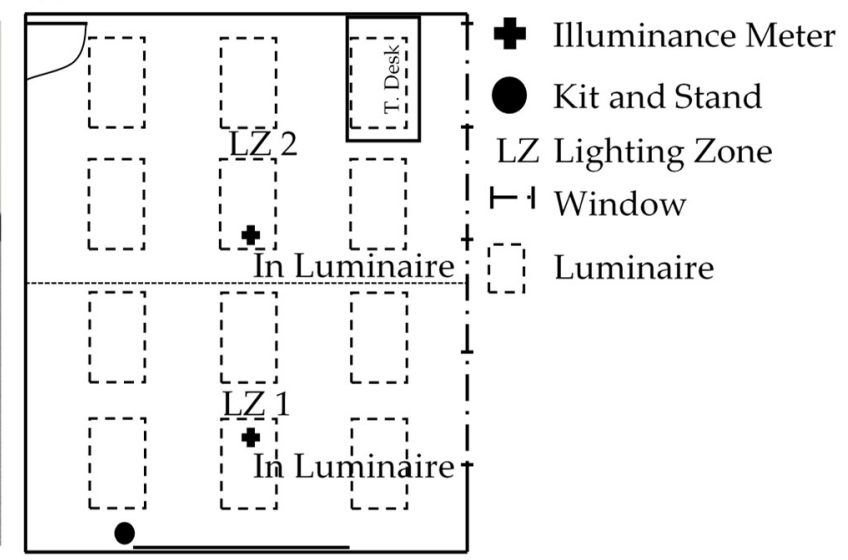

Figure 1. (a) Measurement Kit and Stand; (b) Additional Occupied Measurement Equipment; (c) Example Classroom Floor Plan. 


\subsubsection{Unoccupied Measurements}

Measurements regarding geometry, reflectivity, transmissivities, and orientation were taken for each classroom, including every door, window, and wall to obtain data used for daylight simulations. Illuminance measurements were taken following the IES handbook procedures [29]. In that sense, illuminance measurements were taken with and without the lights on at each location to allow for separation of the daylight from the electric lighting. The student seating area was identified by measurement personnel and then located in each classroom by measuring the distance from each corner and the center of the virtual perimeter of the desks to the north wall (or east wall if windows were located on the north), and the nearest wall with a window. Photos of the interior and outside views of the classroom, as well as fluorescent lamps installed, were used as reference points when developing the daylight models and gathering CCT information. The photos of the classrooms were taken from the corners of the room in a clockwise direction to ensure the entire space was captured. View photos were taken at the four corners and in the center of the student seating area at student eye height $(1.02 \mathrm{~m}$ for elementary students and $1.17 \mathrm{~m}$ for middle and high school) [30]. The view photos provided more information about what the students were able to see when looking outside.

\subsection{Visual Environment Measures}

\subsubsection{Daylight Metrics and Simulation Methodology}

Due to the complexities of conducting continuous measurements in occupied spaces in the long-term, annual hourly simulations were conducted using inputs obtained by the unoccupied measurements. SPOT (Sensor Placement + Optimization Tool) [31], a daylight simulation software, was used to that end. The objective of the simulations was to accurately assess daylighting in each classroom following the general guidelines provided in the IES LM-83 [32]. Each classroom was modeled in SPOT, with the interior portion of the model including all permanent surfaces and objects above work plane height of $30^{\prime \prime}$, and the exterior portion including buildings, trees, and other permanent objects up to $100 \mathrm{ft}$ outside of the classroom windows [32]. Five classrooms were not possible to be modeled due to limitations of SPOT with respect to handling unique geometries (e.g., cut outs containing windows and other complex characteristics). This has led to $2.3 \%$ of missing data for the daylighting metrics. In order to account for the actual exterior weather conditions in the simulation, Actual Meteorological Year (AMY) data set by White Box Technologies [33] were used for the two-year period during which the experiment took place.

Model validation was conducted based on readings of the $\mathrm{HOBO}$ illuminance sensor that was placed on top of the measurement kit. The daylight portion of the total illuminance was calculated after subtracting for the illuminance due to electric lighting. To identify whether electric lighting was on/off at any instance, the readings of the fixtures' illuminance sensors were utilized. The electric lighting could then be properly subtracted throughout the day, allowing direct comparisons with the simulated illuminance values for every point. This method did introduce a slight margin for error, as the HOBO illuminance meter's sensor has a diameter of $6.35 \mathrm{~mm}$, while SPOT calculated measurement covered an area of $0.61 \mathrm{~m}$ by $0.61 \mathrm{~m}$.

One major challenge related to the simulations was the inability to capture the positions of shades and blinds for all measured instances for classrooms. A survey was given to teachers to better understand how they use their shading options. This survey successfully addressed the extreme cases of "I always keep the blinds/shades shut" or "I always keep the blinds/shades open". However, the survey did not help for most cases that would say "I adjust the blinds/shades when sun causes glare for myself or the students". This response was a problem as it is hard to identify which teachers fell into a proactive/passive user category [31]. A proactive user would adjust blinds/shades when problematic daylight occurs and then re-adjust blinds/shades shortly after the problematic daylight has passed. A passive user would adjust the blinds/shades when problematic 
daylighting occurs but would take a significant amount of time to open blinds/shades after the problem has passed. Student privacy rules prevented the use of cameras that would allow accurate logging of shade positions for each data point. A thermal camera solution was utilized for some measurements, but a significant amount of data had already been collected by the time the thermal camera was operational.

Figure 2 shows an example of validation between predicted and measured illuminance over a two-day measurement period during the spring of 2015 in classroom ID 004. The measurements extend to $4 \mathrm{pm}$ of the second day, as the equipment was picked up after that time, following our measurement protocol.

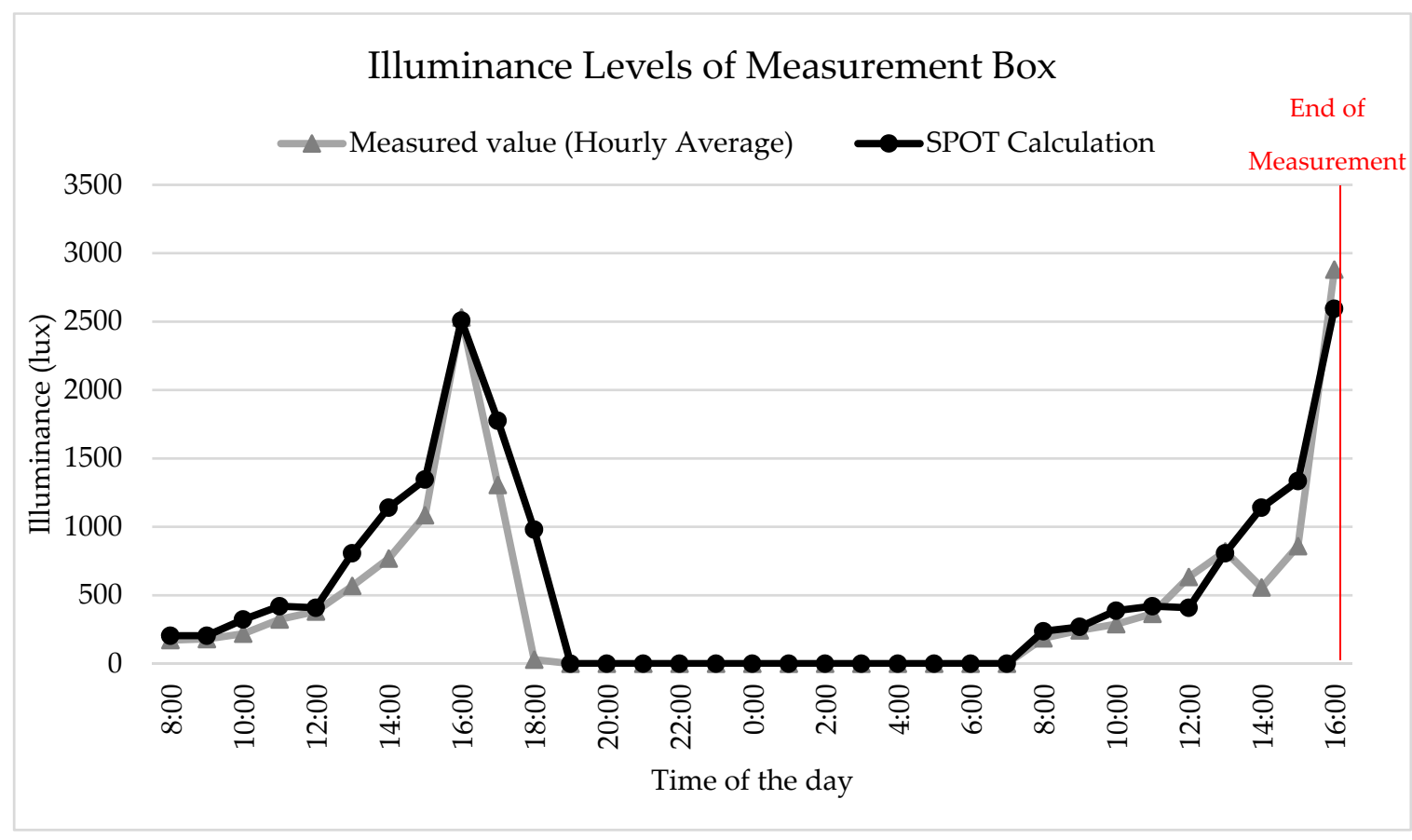

Figure 2. Illuminance Levels of Measurement Box within a Two-Day Measurement Compared to SPOT Calculation.

Minor deviations observed in the figure at different times can be associated with the way cloud coverage is simulated compared to the actual sky conditions. Validations showed an MSRE (mean square root error) of 253.71 lux with an average percent error of $22.2 \%$, which, given the limitations of missing information about shading positions, the HOBO illuminance meter, and other missing data, is considered reasonable and within the percent error discussed in Tregenza [34]; the latter study suggested that single-point-in-time illuminance calculations should vary at a minimum of plus or minus $20 \%$ average percent error, while Sadeghi [35] found an average percent error of $22.8 \%$ using the same model detail level as in this study. After the modeling methodology was considered reasonably accurate, the other classrooms were checked by verifying illuminance levels using pointin-time measurements spread across the six measurement days to ensure model quality. This check involved the same procedure used in Figure 2, but due to the large number of classrooms and generated data, only 4-6 points in time were compared for each season. Corrections were then made to improve the models if errors were found.

The daylighting metrics that were assessed include: (i) Continuous Daylight Autonomy (cDA); (ii) Spatial Daylight Autonomy (sDA); (iii) Useful Daylight Illuminance autonomous + supplementary; (iv) Useful Daylight Illuminance Exceeded; (v) Daylight Factor; and (vi) Annual Sunlight Exposure (ASE) [32,36]. For sDA and ASE, modified versions of the metrics were assessed in order to address methodological differences concerning the time of the analysis; while these two metrics refer to an analysis time between 8 A.M. and 6 P.M., our analysis period was adjusted to reflect school operation, ranging from 8 A.M. to 
3 P.M. Although the calculation approach for the metrics remains unchanged, details for the number of hours for ASE had to be adjusted accordingly.

\subsubsection{Electric Lighting Metrics}

Three electric lighting metrics were used to assess electric lighting in the classrooms:

1. Maximum Average Electric Illuminance Level (calculated in the winter unoccupied measurements using the methodology included in the IES handbook 10th Edition) [29].

2. Time-Weighted Illuminance level based on the illuminance meters placed in the light fixtures. All but six classrooms used fluorescent fixtures with either on/off or 3-level switching options. The remaining six classrooms still used fluorescent but with set-dimming levels. This allowed for the maximum average illuminance to be reduced based on the way teachers used theirs lights during the six days of occupied measurements. In that sense, Time-Weighted Illuminance would provide a more accurate representation of the electric lighting experienced by students.

3. Correlated Color Temperature was considered as a variable of interest based on the findings of previous studies. However, there was little to no variance in the fluorescent lamps used in the measured classrooms, with the CCT ranging from $3000 \mathrm{~K}$ to $3500 \mathrm{~K}$. This was a result of each school district having a specific fluorescent lamp product that they used for every school building within their district. Although variations could be observed based on the impact of daylighting for different window distances, that would involve expensive and obstructive sensing requirements that were considered to be out of scope for this study.

\subsubsection{View Metrics}

The view out from buildings has been gaining interest as a significant part of the visual environment. EN 17037 "Daylight of Buildings" is a European standard that defines view using three different metrics: (1) Horizontal Sight Angle; (2) Outside Distance of View; and (3) Number of View Layers [37].

1. Horizontal Sight Angle defines the amount of available outside view within a space by its visible width. The reference point used for this calculation is the farthest seating point within the utilized space. For this study, the farthest point from the student seating area to the primary window was used.

2. Outside Distance of View defines the extent of outside visual information available within a specific room. More specifically, it is defined in EN17037 as the "distance from the inner surface of view opening to opposite major obstructions located in front of the opening" [37]. An obstruction is defined as "anything outside a building which prevents the direct view of part of the sky" [37]. The Outside Distance of the View is measured from the exterior surface of the view opening (window) to the nearest obstruction outside.

3. The Number of View Layers metric reflects the quality and diversity of visible content and is defined by EN 17037 based on the assumption that there are "three distinct layers comprising a view: a layer of sky, a layer of landscape and a layer of ground" [37]. The landscape layer can be any landscape/urban/natural objects in view, or, in lack of them, the horizon line. Number of view layers seen is to be calculated from at least $75 \%$ of the utilized area within the studied room. Number of layers was evaluated using the photos taken from the farthest corner of the student seating location.

Table 1 shows the way EN17037 evaluates each of these metrics. Number of View Layers for this study was orthogonal contrast-coded, making: (i) a comparison of no layers/no windows to the grouping of one layer, two layers, and all three layers (View vs. No View); and (ii) a comparison of one layer and two layers to all three layers (Two View Layers vs. Three View Layers). A third comparison between one layer and two layers was not possible, as only five classrooms had one layer, therefore these were merged with the two layers cases in the second comparison. Horizontal Sight Angle and Outside Distance 
of the View were treated as continuous variables. Figure 3a shows the Horizontal Sight Angle and Figure $3 \mathrm{~b}$ shows Outside Distance of the View and Number of View Layers.

Table 1. Assessment of View Outwards-Information from EN17037.

\begin{tabular}{cccc}
\hline $\begin{array}{c}\text { Recommendation } \\
\text { Level }\end{array}$ & $\begin{array}{c}\text { Horizontal Sight } \\
\text { Angle }\end{array}$ & $\begin{array}{c}\text { Outside Distance } \\
\text { of the View }\end{array}$ & Number of View Layers \\
\hline Below Minimum & $<14^{\circ}$ & $<6.0 \mathrm{~m}$ & $\begin{array}{c}\text { No layers } \\
\text { Minimum }\end{array}$ \\
Medium & $\geq 24^{\circ}$ & $\geq 6.0 \mathrm{~m}$ & $\begin{array}{c}\text { Landscape layer/one layer } \\
\text { Landscape layer plus one other } \\
\text { layer/two layers }\end{array}$ \\
High & $\geq 50^{\circ}$ & $\geq 20.0 \mathrm{~m}$ & $\begin{array}{c}\text { All layers are included in same } \\
\text { view opening/three layers }\end{array}$ \\
\hline
\end{tabular}

(a)

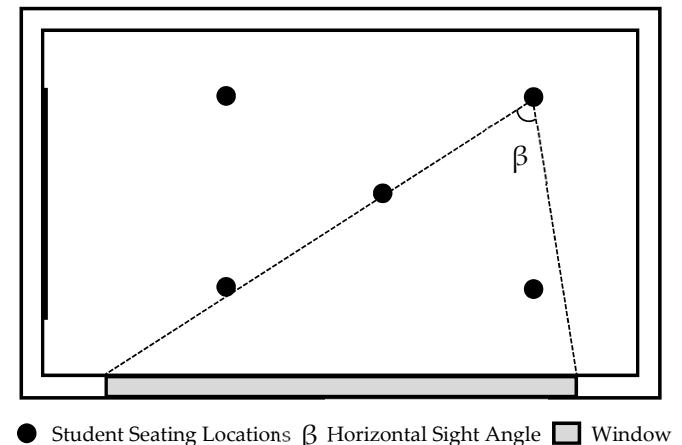

(b)

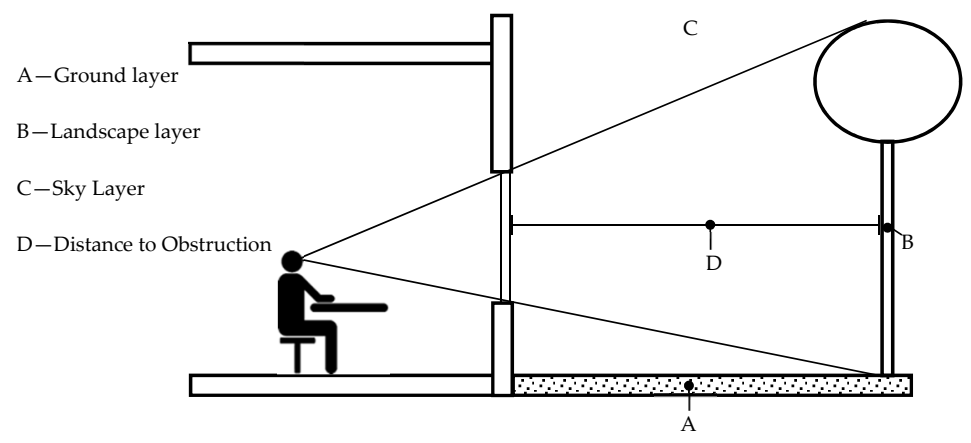

Figure 3. (a) Example Classroom Floor Plan; (b) Example Section Cut for View Metrics.

\subsection{Dependent Measures and Controls}

To gauge the effects of the indoor visual environment on student performance, every school district was asked to provide student achievement scores on standardized tests. The study included classrooms in both Nebraska and Iowa, so the Nebraska State Accountability (NeSA) Assessment scores and the Iowa Test of Basic Skills (ITBS) scores for math and reading were provided on a classroom level. The data was received in national percentile rank allowing comparison between the two standardized tests. As middle school and high school students had to switch classrooms for each subject, math and reading scores were taken only from dedicated math and English/reading classrooms, respectively. In order to control for variations in socioeconomic status and learning ability, each school district provided demographic information for: (i) free and reduced lunch recipients; (ii) gifted learners; and (iii) special education students by classroom percentage. Student grade level is a set of three dummy coded variables to control for the differences among grades. Third grade was used as the reference grade to generate the dummy coded variables. Free and reduced lunch recipients was used as a socioeconomic status control variable as students of below average socioeconomic status become eligible for free or reduced cost for lunch. Gifted learners refer to students that have been assessed by their school district as being high performing and is used to help control for variations in high performing classrooms. Special education students refer to students that have some sort of disability that may impede them from learning as effectively as other students. This variable is used primarily to control for the age of the students, but can also capture differences between elementary, middle, and high school classrooms, as only one grade was tested for the middle and high school levels. 


\section{Results}

\subsection{Descriptive Statistics}

RStudio was used to organize and conduct the statistical analysis using the lavaan package. The Full Information Maximum Likelihood (FIML) approach was used, allowing for missing data to be accurately interpolated. The descriptive statistics for the achievement, demographic, and lighting metrics used in the final model are shown in Table 2.

Table 2. Descriptive Statistics.

\begin{tabular}{|c|c|c|c|c|c|}
\hline Variables & $\mathbf{N}$ & Mean & $\begin{array}{l}\text { Standard. } \\
\text { Deviation }\end{array}$ & Minimum & Maximum \\
\hline Math Achievement (Percentile Rank) & 178 & 56.74 & 14.76 & 18.33 & 95.98 \\
\hline Reading Achievement (Percentile Rank) & 180 & 55.88 & 13.60 & 17.26 & 87.30 \\
\hline$\%$ Free and Reduced Lunch Recipients & 216 & 37.31 & 29.88 & 0.00 & 100.00 \\
\hline \% Special Education Students & 216 & 13.67 & 8.99 & 0.00 & 41.67 \\
\hline \% Gifted Learners & 216 & 13.62 & 13.73 & 0.00 & 76.09 \\
\hline Maximum Average Illuminance (lux) & 216 & 779.69 & 163.97 & 252.21 & 1159.82 \\
\hline Time-Weighted Illuminance (lux) & 216 & 460.15 & 181.08 & 62.14 & 995.10 \\
\hline Spatial Daylight Autonomy (sDA) & 211 & 0.06 & 0.10 & 0 & 0.65 \\
\hline Annual Sunlight Exposure (ASE) & 211 & 0.10 & 0.16 & 0 & 0.82 \\
\hline Uniform Daylight Illuminance (UDI) & 211 & 0.25 & 0.23 & 0 & 0.97 \\
\hline Horizontal Sight Angle & 216 & 42.33 & 34.65 & 0 & 125.28 \\
\hline Number of View Layers & 216 & 2.02 & 1.15 & 0 & 3 \\
\hline
\end{tabular}

Note. $\mathrm{N}$ for achievement is lower as 8 th and 11 th grade have exclusively math or reading classrooms. Some metrics were not used in the final model but are provided here for more information.

Table 2 shows that all variables have good variance except special education. Math Achievement and Reading Achievement have an $\mathrm{N}$ of less than 216 as, for 8th and 11th grade, the classroom was either a math classroom or reading classroom. All variables were tested for normality with histograms. Special Education Students, Gifted Learners, and Annual Sunlight Exposure statistics showed the greatest skew in their histograms. When tested for skew and kurtosis, it was found that only Gifted Learners and Annual Sunlight Exposure had problematic skews, exceeding 1 [38]. However, deviations from normality were expected for these variables, as the Special Education Students or Gifted Learners are subgroups of the student population that have been already identified as different from the average student. As subgroups, Special Education Students and Gifted Leaners are low to zero percentages of the potential population for each classroom. This causes the distribution for each variable to be closely packed toward the zero value. The resulting effect is that the normal distribution is cut-off by the left boundary condition of zero. Annual Sunlight Exposure was expected to be skewed right, as it is an area-based calculation with most classrooms only having windows in one orientation, leading to limited direct sun penetration.

\subsection{Model Discussion}

A multivariate linear regression approach was used for data analysis with a nested structure to account for the school level variations. The linear regression model used for both Reading and Math Achievement with the demographic control variables of Free and Reduced Lunch Recipients, Gifted Learners, Special Education Students, Student Grade Level, and independent variables of Time-Weighted Illuminance, Annual Sunlight Exposure, Horizontal Sight Angle, and Number of View Layers (View vs. No View and Two View Layers vs. Three View Layers). All linear regression assumptions were checked and found to be satisfactory. It is worth noting that several metrics did not make it into the linear regression model, mainly due to conflicts these metrics create within the model: (i) Number of View Layers and Outside Distance of the View not being independent from each other; as Outside Distance of the View increases, so does the Number of View Layers. This led to Outside Distance of the View being dropped due to Number of View Layers 
also containing a qualitative aspect of view. (ii) Maximum Average Illuminance and TimeWeighted Illuminance were dependent, as Time-Weighted Illuminance is calculated from the Maximum Average Illuminance. In that sense, Maximum Average Illuminance was dropped, as it was theorized that Time-Weighted Illuminance would represent illuminance levels closer to what students experienced; (iii) the two-daylight metrics use the same illuminance data for calculation, leading to a similar dependency problem. Annual Sunlight Exposure was chosen to stay in the model, as it was considered more suitable to capture only the negative aspect of daylight. Useful Daylight Illuminance (UDI) was considered as an alternative, it was rejected due to the use of bins that would still have a strong correlational relationship with each other, not truly separating the daylight properly from a statistical perspective. The orientation of the window providing view to the outside was considered for the model, as previous literature showed an effect on student achievement [4]. However, this was not included in the models due to singularities that occurred between variables when interactions between window orientation and the other visual metrics were tried. A singularity occurs when a value on one independent variable perfectly predicts the value of a different independent variable. In our data set, the window orientation variable when the classroom had no windows perfectly predicted the values for Annual Sunlight Exposure, Number of View Layers, and Horizontal Sight Angle, something that was impossible to overcome due to the respective definition of the metrics. Correlated Color Temperature was also dropped from the model due to the issues discussed earlier relating to low variance and school districts using one type of lamp for the whole school district.

\subsection{Student Achievement Models}

Table 3 shows the multivariate regression of Reading Achievement on the selected visual metrics. The multivariate regression is a correlational analysis, as the data was gathered in actual classrooms where the environment has not been manipulated to exercise experimental control. Instead, statistical control was used by including demographic variables to limit confounding factors. Interactions between all combinations of demographic and visual metrics were tested, however, what was included in the model was only interactions that were significant when tested individually. If an interaction is found to be significant, the main effect of a metric should not be interpreted without also evaluating the interaction simultaneously. In that sense, the View or No View comparison has a significant positive effect on Reading Achievement, implying that having a view to the outside of a classroom promotes higher reading scores. The reading model does contain a significant interaction found between Horizontal Sight Angle and Free and Reduced Lunch Recipients. Horizontal Sight Angle has a significant negative interaction with Free and Reduced Lunch Recipients, showing that as Free and Reduced Lunch Recipients increases, the effect of Horizontal Sight Angle on Reading Achievement decreases (Figure 4). That negative interaction could be associated with (i) allowing for additional heat gain and potential glare from the sun, or (ii) the potential for more distractions to occur outside with an increased view angle. An interesting note is that, for classrooms with low Free and Reduced Lunch Recipients, Horizontal Sight Angle has a significant positive effect on Reading Achievement. The positive effect can be clearly seen in Figure 4. Table 4 presents the multivariate regression for Math Achievement on the selected visual metrics. No independent variables were found to be significant for the math model. 
Table 3. Multivariate Regression of Reading on Demographics and Lighting Metrics.

\begin{tabular}{|c|c|c|c|c|c|}
\hline Reading Model & B & SE & $\beta$ & $\mathbf{R}^{2}$ & $95 \% \mathrm{CI}$ \\
\hline Intercept & 61.56 & & & 0.536 & \\
\hline$\%$ Free and Reduced Lunch Recipients & -0.05 & 0.03 & -0.10 & & {$[-0.24,0.04]$} \\
\hline$\%$ Gifted Learners & 0.60 & 0.06 & $0.61 * *$ & & {$[0.48,0.73]$} \\
\hline \% Special Education Learners & -0.27 & 0.09 & $-0.18^{* *}$ & & {$[-0.29,-0.07]$} \\
\hline Grade 5 & -4.23 & 2.05 & $-0.15^{*}$ & & {$[-0.28,-0.01]$} \\
\hline Grade 8 & -3.55 & 3.20 & -0.09 & & {$[-0.26,0.07]$} \\
\hline Grade 11 & -13.02 & 3.16 & $-0.37^{* *}$ & & {$[-0.55,-0.20]$} \\
\hline Time-weighted Illuminance $\left(\mathrm{E}_{\mathrm{TW}}\right)$ & -0.01 & 0.01 & -0.09 & & {$[-0.23,0.05]$} \\
\hline Annual Sunlight Exposure (ASE) & 5.29 & 4.52 & 0.06 & & {$[-0.04,0.17]$} \\
\hline View vs. No View & 0.76 & 0.36 & $0.11 *$ & & {$[0.01,0.21]$} \\
\hline Two View Layers vs. Three View Layers & 0.05 & 1.28 & 0.00 & & {$[-0.14,0.14]$} \\
\hline Horizontal Sight Angle (HSA) & 0.06 & 0.02 & $0.16^{* *}$ & & {$[0.04,0.28]$} \\
\hline HSA $x \%$ Free lunch & -0.002 & 0.0007 & $-0.42^{* *}$ & & {$[-0.64,-0.21]$} \\
\hline
\end{tabular}

Note. $\mathrm{N}=180 .{ }^{*} p<0.05$. ${ }^{* *} p<0.01$. B: Unstandardized Coefficient; SE: Standard Error; $\boldsymbol{\beta}$ : Standardized Coefficient; $\mathbf{R}^{2}$ : variance accounted for a dependent variable by the independent variables; $95 \%$ CI: 95\% Confidence Interval of the Standardized Coefficient.

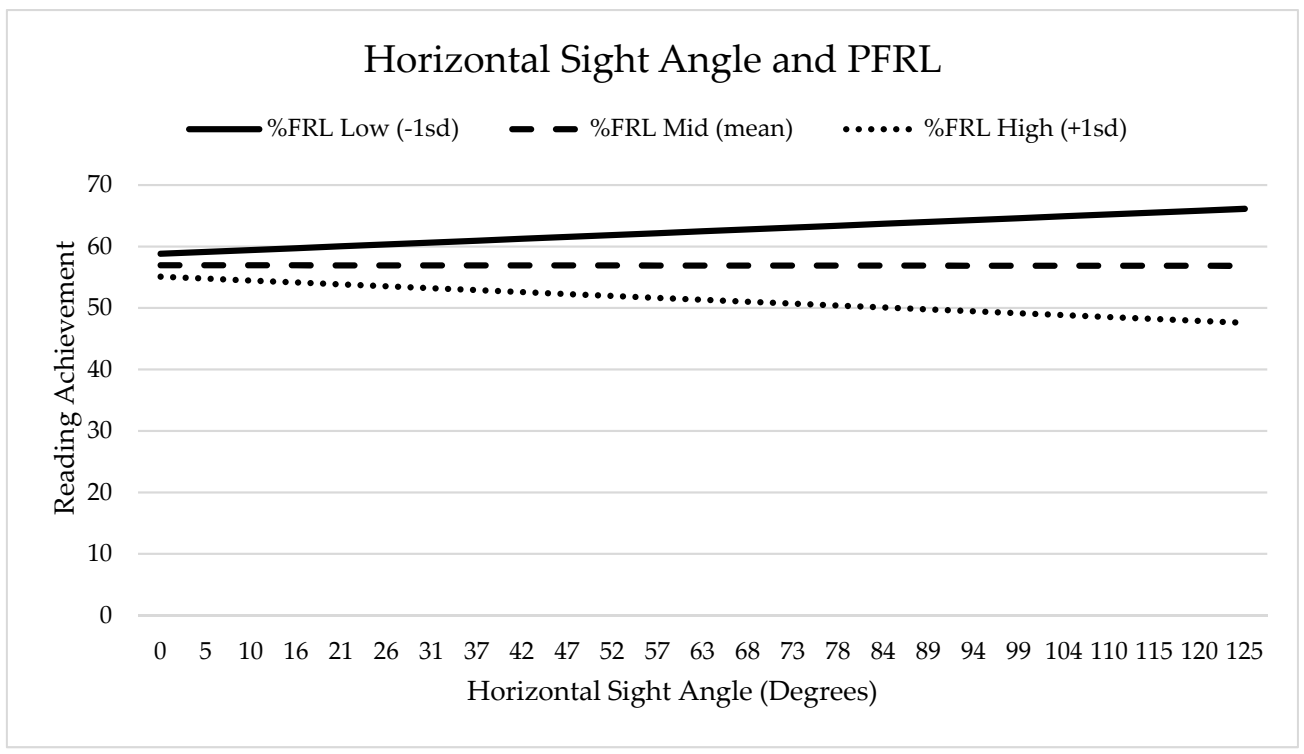

Figure 4. Interaction Plot for Horizontal Sight Angle and \% Free and Reduced Lunch Students on Reading Achievement.

Table 4. Multivariate Regression of Math Achievement on Demographics and Lighting Metrics.

\begin{tabular}{|c|c|c|c|c|c|}
\hline Math Model & B & SE & $\beta$ & $\mathbf{R}^{2}$ & $95 \% \mathrm{CI}$ \\
\hline Intercept & 68.80 & & & 0.626 & \\
\hline$\%$ Free and Reduced Lunch Recipients & -0.23 & 0.04 & $-0.46^{* *}$ & & {$[-0.60,-0.32]$} \\
\hline$\%$ Gifted Learners & 0.31 & 0.15 & $0.29 *$ & & {$[0.02,0.55]$} \\
\hline$\%$ Special Education Learners & -0.32 & 0.08 & $-0.19 * *$ & & {$[-0.29,-0.09]$} \\
\hline Grade 5 & -2.48 & 2.05 & -0.08 & & {$[-0.21,0.05]$} \\
\hline Grade 8 & -4.13 & 2.36 & -0.10 & & {$[-0.21,0.01]$} \\
\hline Grade 11 & -3.31 & 2.65 & -0.09 & & {$[-0.22,0.05]$} \\
\hline Time-weighted Illuminance $\left(\mathrm{E}_{\mathrm{TW}}\right)$ & -0.01 & 0.01 & -0.09 & & {$[-0.21,0.04]$} \\
\hline Annual Sunlight Exposure (ASE) & -0.01 & 3.95 & 0.00 & & {$[-0.08,0.08]$} \\
\hline View vs. No View & 0.11 & 0.48 & 0.01 & & {$[-0.11,0.14]$} \\
\hline Two View Layers vs. Three View Layers & -1.83 & 1.43 & -0.09 & & {$[-0.24,0.05]$} \\
\hline Horizontal Sight Angle (HSA) & -0.03 & 0.03 & -0.07 & & {$[-0.21,0.07]$} \\
\hline$E_{t w} \times \%$ Gifted Learners & 0.00 & 0.00 & 0.24 & & {$[-0.01,0.49]$} \\
\hline
\end{tabular}

Note. $\mathrm{N}=178 .{ }^{*} p<0.05 .{ }^{* *} p<0.01$. B: Unstandardized Coefficient; SE: Standard Error; $\boldsymbol{\beta}$ : Standardized Coefficient; $\mathbf{R}^{2}$ : variance accounted for a dependent variable by the independent variables; 95\% CI: 95\% Confidence Interval of the Standardized Coefficient. 


\section{Discussion, Limitations, and Future Work}

The significant positive effect of the View vs. No View on Reading Achievement can be justified by the fact that EN17037 states that having a view to the outside can relieve the fatigue associated with long periods of being indoors [37]. This finding also agrees with findings from Heschong Mahone Group [4]. The View vs. No View effect is particularly notable as, considering that window size is being accounted for by the Horizontal Sight Angle, it implies that the effect of Horizontal Sight Angle and its interaction with having a view out still matters. This advocates to the fact that view is a multifaceted concept and has far more intricacies to consider regarding how view out of classrooms effects student achievement. The Two View Layers vs. Three View Layers comparison was not significant, indicating there is no major difference between having two view layers or three. Unfortunately, the lack of classrooms that only had one layer prevent a comparison with that group. This is primarily as the Midwest, United States has low population density, resulting in buildings not being tightly packed and limiting the access to view.

The significant interaction found between Horizontal Sight Angle and Free and Reduced Lunch Recipients cannot be fully explained in as naturalistic an experiment as the one conducted; however, the authors hypothesize that students of the high Free or Reduced Lunch group could be more prone to not having a beneficial learning or reading environment at home, causing the distractive effects of the classroom environment to be amplified. Previous research focused on the socioeconomic status (SES) of students corroborate that home environments can be a critical factor influencing learning and achievement; for low socioeconomic status (SES) communities in California, the average number of books present in the home was just six books, versus high SES that had an average of 414 books [39]. Interviewing parents of high achieving, low SES students showed that they made sure to find ways to provide materials and support systems to create strong learning environments at home [40]. In that sense, future studies should include inputs related to the learning environment at home to better understand possible interactions. Surveys that were deployed to the teachers showed that there were observations of students being distracted from looking outside; however, the ambiguity of this finding, as well as the potential conflict with the positive effect of the View vs. No View comparison advocates for further examination in a controlled study to achieve more conclusive results.

The main limitations to this project are directly connected to the correlational and naturalistic approach of the study. Due to this approach, it is still possible for confounding effects to occur. Proceeding with a correlational naturalistic study was a decision the authors made to minimize disruption to the students, leading to access to a wider sample. Using standardized testing was beneficial for not interfering with students, but also presented the limitation of only having access to the aggregated score in the classroom level. This prevented a deeper level of analysis and control over the project. The inability to accurately capture blind usage was another limitation inherent to our approach of causing minimum disturbance in the flow of the educational process in classrooms. Addressing this would require either the placement of cameras in the classrooms, requiring permissions from over 8000 parents, or other intrusive and expensive solutions that would not be feasible for that many classrooms.

This study represents a fraction of the overall research conducted for this research grant, as other studies were focused on acoustics, thermal sensation, and indoor air quality. All studies will also be combined and analyzed to evaluate what aspects or interactions of them within the classroom environment have the greatest impact on student achievement. This information will help to inform school districts and building industry on important environmental guidelines for increasing student achievement and well-being. As similar research grants were given out by the EPA to six other research groups [41] there is a potential for meta-analysis, aiming to strengthen and verify the findings of all groups and bringing a better understanding of the indoor environmental effects on student achievement. Future research related to studying students in primary and secondary education should focus on installing as many experimental controls as possible without severely limiting sample size. 
One of the best ways to do this is to create custom exams for each subject of interest since, as stated above, standardized testing limits experimental control though reliance on school districts to provide data, as well as the administration of the standardized exams. Due to factors such as the need not to compromise everyday classroom activities and to comply with the privacy requirements for students, one of the most feasible ways to continue research on the impact of the indoor environment on students are large scale correlational analyses. This approach does not heavily rely on direct student involvement, thus cannot compromise the students' ability to learn. Such analyses could be more specifically targeted, focusing on classrooms that are similar in layout and demographics but vary only in terms of window size or other view out parameters. In addition, research related to view should expand on the way occupants use their visual environment. Towards such objectives, eye tracking technology could prove to be a major asset, as it can provide real-time understanding of the role of window views in the context of different tasks.

\section{Conclusions}

The goal of this study was to identify visual environmental factors that impact student achievement using objective-based measurements. These allow for the conclusions drawn from this study to be replicated and comparable to future study results by eliminating observer bias and rater fatigue. It was found that, for Reading Achievement, there was a positive effect of having access to view out of the classroom. However, there was also a significant negative interaction between Horizontal Sight Angle and Free and Reduced Lunch Recipients on Reading Achievement. This interaction showed that for students that may experience additional struggles outside of school, more access to views may augment tendencies for distraction or amplify negative effects of direct sun into the classroom. It also shows that for students that may not have these same difficulties, Horizontal Sight Angle is beneficial. These results specifically point to the fact that more research needs to be conducted related to view due to the complicated relation found between view and student achievement. View appears to be a multifaceted concept that may have distinct benefits in certain situations but negative elements in others. This can have implications in design guidelines for schools, where architects should be encouraged to allocate classrooms with windows but try to limit potential distractions outside of windows and minimize potential glare.

Author Contributions: Conceptualization, C.E.W.; Data curation, M.K.; Formal analysis, M.K.; Funding acquisition, C.E.W.; Investigation, M.K. and C.E.W.; Methodology, M.K. and C.E.W.; Project administration, C.E.W.; Software, M.K.; Supervision, I.K. and C.E.W.; Validation, M.K., I.K. and C.E.W.; Visualization, M.K.; Writing-Original draft, M.K.; Writing—Review \& editing, I.K. and C.E.W. All authors have read and agreed to the published version of the manuscript.

Funding: This research was funded by United States Environmental Protection Agency, grant number R835633.

Institutional Review Board Statement: IRB oversight was not required due to not directly interacting with students and the data received being at classroom level and not individual.

Informed Consent Statement: Informed consent was not required on an individual level as students were not interacted with directly and no individual information was acquired. However, school district level consent was given by each school district.

Data Availability Statement: 3rd Party Data Restrictions apply to the availability of these data. Some data was obtained from Nebraska and Iowa school districts and are available from the authors with the permission of Nebraska and Iowa school districts. Contact the authors for help obtaining permission.

Acknowledgments: The authors would like to acknowledge the other investigators on this grant, namely Lily Wang, James Bovaird, and Josephine Lau. The authors would also like to thank the Project Advisory Committee and particularly Richard Mistrick on the advice given throughout the 
project. A special thank you to the school districts for their cooperation and allowing us to conduct measurements within their schools.

Conflicts of Interest: The authors declare no conflict of interest.

\section{References}

1. Butler, D.L.; Biner, P.M. Effects of Setting on Window Preferences and Factors Associated with Those Preferences. Environ. Behav. 1989, 21, 17-31. [CrossRef]

2. Ulrich, R.E. View through a window may influence recovery. Am. Assoc. Adv. Sci. 1984, 224, 420-421. [CrossRef]

3. Aries, M.B.; Veitch, J.A.; Newsham, G.R. Windows, View, and office characteristics predict physical and psychological discomfort. J. Environ. Psychol. 2010, 30, 533-541. [CrossRef]

4. Heschong Mahone Group. Windows and Classrooms: A Study of Student Performance and the Indoor Environment; California Energy Commission: Sacramento, CA, USA, 2003.

5. Durán-Narucki, V. School building condition, school attendance, and academic achievement in New York City public schools; A mediation model. J. Environ. Psychol. 2008, 28, 278-286. [CrossRef]

6. Konstantzos, I.; Sadeghi, S.A.; Kim, M.; Xiong, J.; Tzempelikos, A. The effect of lighting environment on task performance in buildings-A review. Energy Build. 2020, 226, 110394. [CrossRef]

7. Mott, M.S.; Robinson, D.H.; Walden, A.; Burnette, J.; Rutherford, A.S. Illuminating the Effects of Dynamic Lighting on Student Learning. SAGE Open 2012, 2, 1-9. [CrossRef]

8. Bowers, J.; Burkett, C. Physical environment influences related to student achievement, health, attendance, and behavior. CEFP J Counc. Educ. Facil. Plan. J. 1988, 26, 33-34.

9. Phillips, R.W. Educational Facility Age and the Academic Achievement and Attendance of Upper Elementary School Students. Unpublished Ph.D. Thesis, University of Georgia Athens, Athens, GA, USA, 1997.

10. Plumley, J.P. The Impact of School Building Age on the Academic Achievement of Pupils from Selected Schools in the State of Georgia. Unpublished Ph.D. Thesis, University of Georgia Athens, Athens, GA, USA, 1978.

11. Chan, T.C. The Impact of School Building Age on the Achievement of Eighth-Grade Pupils from the Public Schools in the state of Georgia. Unpublished Ph.D. Thesis, University of Georgia Athens, Athens, GA, USA, 1979.

12. Cuttle, K. People and Windows in Workplaces. In Proceedings of the Conference on People and Physical Environment Research, Wellington, New Zealand, 8-11 June 1983; pp. 203-212.

13. Boubekri, M.; Hull, R.B.; Boyer, L.L. Impact of Window Size and Sunlight Penetration on Office Workers' Mood and Satisfaction. Environ. Behav. 1991, 23, 474-493. [CrossRef]

14. Tennessen, C.M.; Cimprich, B. Views to nature: Effects on attention. J. Environ. Psychol. 1995, 15, 77-85. [CrossRef]

15. Tuaycharoen, N.; Tregenza, P. View and discomfort glare from windows. Light. Res. Technol. 2007, 39, 185-200. [CrossRef]

16. Boyce, P.R.; Veitch, J.; Newsham, G.R.; Jones, C.C.; Heerwagen, J.; Myer, M.; Hunter, C.M. Lighting quality and office work: Two field simulation experiments. Light. Res. Technol. 2006, 38, 191-223. [CrossRef]

17. Veitch, J.; Newsham, G.; Boyce, P.; Jones, C. Lighting appraisal, well-being, and performance in open-plan offices: A linked mechanisms approach. Light. Res. Technol. 2008, 40, 133-151. [CrossRef]

18. Nicklas, M.H.; Bailey, G.B. Analysis of the Performance of Students in Daylit Schools; Unpublished Manuscript of Innovative Design: Raleigh, NC, USA, 1995.

19. Pierson, C.; Wienold, J.; Bodart, M. Review of Factors Influencing Discomfort Glare Perception from Daylight. LEUKOS 2017, 14, 111-148. [CrossRef]

20. Grangaard, E.M. Color and Light Effects on Learning. (Report No. PS 023 272). Education Resources Information Center Report; 1995. Available online: https://eric.ed.gov/?id=ED382381 (accessed on 7 October 2020).

21. Wohlfarth, H. Color and Light Effects on Students' Achievement Behavior, and Physiology; Alberta Education: Edmonton, AB, Canada, 1986.

22. London, W. Full-spectrum classroom light and sickness in pupils. Lancet 1987, 330, 1205-1206. [CrossRef]

23. Hathaway, W.E.; Hargreaves, J.A.; Thompson, G.W.; Novitsky, D. A Study into the Effects of Light on Children of Elementary School Age a Case of Daylight Robbery, Policy and Planning Branch, Planning, and Information Services Division; Alberta Education: Edmonton, AB, Canada, 1992.

24. McColl, S.; Veitch, J. Full-spectrum fluorescent lighting: A review of its effects on physiology and health. Psychol. Med. 2001, 31, 949-964. [CrossRef]

25. Berman, S.; Navvab, M.; Martin, M.; Sheedy, J.; Tithof, W. A comparison of traditional and high colour temperature lighting on the near acuity of elementary school children. Light. Res. Technol. 2006, 38, 41-49. [CrossRef]

26. Sleegers, P.; Moolenaar, N.; Galetzka, M.; Pruyn, A.T.; Sarroukh, B.; Van Der Zande, B. Lighting affects students' concentration positively: Findings from three Dutch studies. Light. Res. Technol. 2012, 45, 159-175. [CrossRef]

27. Keis, O.; Helbig, H.; Streb, J.; Hille, K. Influence of blue-enriched classroom lighting on students' cognitive performance. Trends Neurosci. Educ. 2014, 3, 86-92. [CrossRef]

28. Samani, S.A.; Samani, S.A. The Impact of Indoor Lighting on Students Learning Performance in Learning Environments: A knowledge internalization perspective. Int. J. Bus. Soc. Sci. 2012, 3, 127-136. 
29. DiLaura, D.L.; Houser, K.W.; Mistrick, R.G.; Steffy, G.R. The Lighting Handbook: Reference and Application; Illuminating Engineering Society: New York, NY, USA, 2011.

30. Shaikh, F. 4 Common Posture's Dimension to Keep in Mind before Designing Furniture for Children up to 5 to 16 Years. Available online: https://gharpedia.com/blog/4-common-postures-dimension-to-keep-in-mind-before-designing-furniturefor-children-up-to-5-to-16-years/ (accessed on 14 October 2020).

31. Rogers, Z. 1.0 Introduction-SPOT Pro v.5-5.0. SPOT Manual. Available online: https://www.manula.com/manuals/zrogers/ spot-pro-v-5/1/en/topic/1-0-introduction (accessed on 7 October 2020).

32. Illuminating Engineering Society. Approved Method: IES Spatial Daylight Autonomy (sDA) and Annual Sunlight Exposure (ASE); Illuminating Engineering Society: New York, NY, USA, 2012.

33. Huang, J. About WBT Weather Data. White Box Technologies Weather Data for Energy Calculations. Available online: http: / / weather.whiteboxtechnologies.com/aboutdata (accessed on 15 March 2018).

34. Tregenza, P. Uncertainty in daylight calculations. Light. Res. Technol. 2016, 49, 1-16. [CrossRef]

35. Sadeghi, R. Study of Building Surrounding Luminous Environment Using High Dynamic Range Image-Based Lighting Model. Unpublished Ph.D. Thesis, Pennsylvania State University, State College, PA, USA, 2017.

36. Illuminating Engineering Society. Recommended Practice for Daylighting Buildings; Illuminating Engineering Society: New York, NY, USA, 2013.

37. Technical Committee CEN/TC 169. Daylight of Buildings; European Committee for Standardization: Brussels, Belgium, 2018.

38. Bulmer, M.G. Principles of Statistics; Dover Publications Inc.: Dover, UK, 1979.

39. Constantino, R. Print environments between high and low socioeconomic status communities. Teach. Libr. 2005, $32,22-25$.

40. Milne, A.; Plourde, L.A. Factors of a Low-SES Household: What Aids Academic Achievement. J. Instr. Psychol. 2006, 33, 183-193.

41. United States Environmental Protection Agency. Healthy Schools: Environmental Factors, Children's Health and Performance, and Sustainable Building Practices. Available online: https://cfpub.epa.gov/ncer_abstracts/index.cfm/fuseaction/recipients. display/rfa_id/568/records_per_page/ALL (accessed on 7 October 2020). 